\title{
Statin-induced myopathy in a usual care setting-a prospective observational study of gender differences
}

\author{
Ilona Skilving ${ }^{1} \cdot$ Mats Eriksson $^{2} \cdot$ Anders $^{\text {Rane }}{ }^{1} \cdot$ Marie-Louise Ovesjö $^{1}$ (I)
}

Received: 21 February 2016 / Accepted: 19 July 2016 / Published online: 2 August 2016

(C) The Author(s) 2016. This article is published with open access at Springerlink.com

\begin{abstract}
Purpose The study aims to identify the occurrence and remission of statin-induced myopathy including patient perception and symptom characteristics with a gender perspective. Methods The study was designed as a prospective, noninterventional investigation in 192 outpatients receiving statin treatment in usual care with 12 months follow-up. Main outcome measure was myopathy related to statin treatment and classified as probable using WHO criteria for adverse drug reaction (ADR) assessment.

Results Fourteen percent developed myopathy, risk ratio for women 1.52 [95\% CI $1.37 ; 1.66]$ as compared to men. The majority graded their pain as "severe." CK values were within normal range. Eighty percent of the women compared to $43 \%$ of the men reported that the muscular symptoms affected their daily life activities to a moderate or severe extent. For those who stopped treatment, mypopathy was the reason for $70 \%$ of the women and $25 \%$ of the men. There was a difference in mean dose between men with and without myopathy, but not in women. Among the patients with myopathy, $76 \%$ reported other ADRs as compared to $21 \%$ of the patients without
\end{abstract}

Electronic supplementary material The online version of this article (doi:10.1007/s00228-016-2105-2) contains supplementary material, which is available to authorized users.

Marie-Louise Ovesjö

marie-louise.ovesjo@ki.se

1 Division of Clinical Pharmacology, Department of Laboratory Medicine, Karolinska University Hospital Huddinge, 141 86 Stockholm, SE, Sweden

2 Department of Endocrinology, Metabolism and Diabetes; Center for Biosciences, Department of Medicine, Karolinska Institutet, Karolinska University Hospital Huddinge, 14186 Stockholm, SE, Sweden myopathy $(p=0.002)$. Twenty-nine percent of the women and $18 \%$ of the men reported other ADRs.

Conclusion Women reported a higher frequency of myopathy and other ADRs as well as a larger impact on daily life activities. In men, but not in women, the risk of myopathy was dose-dependent. Patients with myopathy were more susceptible to other statin-induced ADRs which raises the question about common underlying mechanisms.

Keywords Statin $\cdot$ Clinical study $\cdot$ Myopathy $\cdot$ Gender . Adverse drug reaction

\section{Introduction}

HMG Co-A reductase inhibitors have proven to efficiently lower serum concentration of low-density lipoprotein cholesterol (LDL-C-C) and to reduce the risk of cardiovascular disease (CVD). Since their introduction in the mid-80s, the indication for using statins in clinical practice has been wellestablished and few other drugs have been so widely used for such a long time [1-6]. Generic statins remain a corner stone in CVD prevention. New lipid modifying drugs such as PCSK9 inhibitors are available but are not considered costeffective for the majority of patients [7]. The withdrawal of cerivastatin in 2001 highlighted the ability of statins to cause more or less severe myopathy including e.g., rhabdomyolysis. Today, the frequency is considered to range from $5[8,9]$ to $15 \%[10,11]$ depending on definition of myopathy and study design. Several studies have indicated that women seem to be more susceptible for muscular adverse drug reactions (ADRs) than men, especially elderly women. The reasons for these differences are unknown. Little attention has been paid to sex differences and myopathy [12]. In general, women were underrepresented in early large scale randomized trials such as 
the 4S study (19\%), the CARE study (14\%), the LIPID study $(17 \%)$, and more surprisingly also in more recent studies such as the PROVE-IT study (22\%) [13-16]. The PRIMO study and the JUPITER study included more women, 35 and $38 \%$, respectively [17-21]. Regardless of the reported frequency of ADRs, myopathy in routine care is a clinical dilemma and could constitute a major reason for the poor adherence to statin therapy that has been demonstrated in many studies [11, 22-24]. Statin treatment differs between women and men as was recently shown by Ballo et al. who also demonstrated that the benefits were equal if the same dose was used, but side effects was not within the scope of this study [25].

In this study, we sought to investigate the statin use and statin management in usual care with the gender disparities as main focus. We sought to identify the occurrence and remission of myopathy and include patient perception and symptom characteristics. Aware of the sensitive task to collect data on muscular side effects without interfering with the patient's own perception, we chose a pragmatic study design, allowing both patients that were statin naïve and patients that switched the statin to be included. This design shortened our timelines allowing the study team to follow naïve subjects "into myopathy" and myopathy patients "to remission" during 12 months in usual care.

\section{Methods}

\section{Study design}

The study was designed as a prospective, non-interventional investigation in outpatients receiving statin treatment during a 12 month period. It encompassed 192 patients from 20 sites (primary care and cardiology outpatient clinics) in the Stockholm County. Swedish speaking patients older than 18, who in the opinion of their physician should start statin treatment or switch to another statin, were included. No intervention with the selection of patients or with statin management was made. Patients were followed for 12 months with two or three visits. Visits took place at start of the study, at 13 months, 6-9 and at 9-12 months thereafter. The first eligible patient was included in June 2007, and last patient visit was in December 2010.

\section{Ethics}

This study was approved by the Regional Ethics Committee in Stockholm and the Swedish Medical Products Agency (MPA) EudraCT 2006-00,486-34. The study complied with the Declaration of Helsinki of The World Medical Association and the International Conference of Harmonization Guideline of Good Clinical Practice (ICH-GCP, E6).

\section{Participants and clinical procedures}

All participants signed an informed consent before the start of the study. We used case report forms (paper or electronic), patient questionnaires, and standardized interviews for data capturing. Medical history included information on previous and current CVD, other diseases and life style factors e.g., smoking status, alcohol intake, and exercise. Information on concomitant medication was collected and categorized by ability to interact with CYP3A4 metabolism. Physical examination included blood pressure, waist circumference, bodyweight, and height. CVD risk classification was performed according to Reiner et al. [26]. Blood samples were analyzed for total plasma cholesterol (TPC), low density lipoprotein cholesterol (LDL-C), high density lipoprotein cholesterol (HDL-C), triglycerides (TG), apolipoprotein $\mathrm{A} 1$ and $\mathrm{B}$, creatinine kinase $(\mathrm{CK})$, myoglobulin, creatinine, hs-CRP, thyroid stimulating hormone (TSH), aspartate aminotransferase (AST), and alanine aminotransferase (ALT). Blood samples were analyzed at the Karolinska University Laboratory.

\section{Patient questionnaires and standardized interviews}

The questionnaires covered muscular symptoms, other symptoms known to be related to statin treatment, daily life activities, statin compliance, educational level, lifestyle factors, and VAS EQ-5D (quality of life instrument) [27]. There were fixed response alternatives on muscle symptoms and their impact on daily life activities on a four-step categorical scale and on a numerical scale (NRS, 1-10). For quality of life measurement, we used EQ-5D self-rated VAS scale (graded 1-100) the two endpoints, labeled 1 = "worst imaginable health" and $100=$ "best imaginable health."

\section{Definition of muscular adverse drug reaction}

To define myopathy, we used the criteria of the American College of Cardiology (ACC), American Heart Association (AHA), and National Heart, Lung, and Blood institute (NHLBI) [24]. The ADRs from muscles and the time to onset were assessed only in the "de novo treated" patients. In the "switch" group, we assessed if muscular symptoms improved after the statin switch. Time to onset was categorized as 0-90, 91-180, 181-270, or $>270$ days after start.

\section{ADR evaluation}

The endpoint evaluation of ADRs was based on physicians' reports, patient questionnaires, and standardized telephone interviews and reviews of patients' medical records. An increase of two grades on the NRS and/or one step at the categorical 
scale was considered clinically relevant. Symptoms meeting these criteria were assessed and classified as "probable" or "possible" according to WHO, or neither "probable" nor "possible" [28].

Other ADRs such as gastrointestinal symptoms or headache are referred to as "other ADRs, only the ones assessed as "probable" were included. An increase of two grades on the NRS and/or one step at the categorical scale was considered clinically relevant.

All patients who were eligible and who initiated statin treatment or made a switch were included in the full analysis set and are presented in Table 1. All patients included in the analysis reported that they took their statin 5-7 days per week. Baseline characteristics and data from primary endpoint analysis are presented for all patients who started with statin treatment and continued to first follow-up. In the analysis of myopathy, only de novo patients with a probable ADR were included.

Statistics Independent $t$ test and Fisher's test exact (twosided) were used to compare factors in the myopathy group with the group without myopathy. The responses to daily life activity (DLA) were dichotomized.

All results are expressed as means $\pm \mathrm{SD}$, or proportion/ percentages for parametric and non-parametric data, respectively. All analyses and descriptive data were performed using SPSS 22.0.

\section{Equipotent doses}

Simvastatin was the most widely used statin in Sweden during the study period and was therefore used as a reference drug for equipotent doses (based on their ability to lower LDL): simvastatin 5-10 $\mathrm{mg}=$ pravastatin 10 $20 \mathrm{mg}=$ fluvastatin $20-40 \mathrm{mg}$. Simvastatin $20 \mathrm{mg}=$ pravastatin $40 \mathrm{mg}=$ atorvastatin $5 \mathrm{mg}$. Simvastatin $40 \mathrm{mg}=$ rosuvastatin $10 \mathrm{mg}=$ atorvastatin $10 \mathrm{mg}$ [29].

\section{Results}

\section{Patient flow and patient characteristics at study start}

One hundred ninety-two individuals were screened for study participation whereof 12 subjects were assessed as screening failures. Of the remaining 180 eligible individuals, 120 were "de novo" patients and 60 "switch" patients, whereof 49 and $50 \%$ females, respectively. Seventy-eight percent of the women completed the study and $86 \%$ of the men. Of those who pre-terminated the study, $70 \%$ of the women and $25 \%$ of the men did so due to muscular symptoms.

At baseline, $35 \%$ of the women and $58 \%$ of the men stated no muscular symptoms. Of the patients experiencing muscular symptoms at study start (pain, weakness, soreness), $65 \%$ of the women and $42 \%$ of the men described "mild" or "moderate" problems with a mean pain score (NRS) 2.9 (SD 3.2) for women and 1.9 (SD2.6) as "moderate" $(p=0.01)$. No patient described their muscular status as "severe" at study start. Patient characteristics are summarized in Table 1.

\section{Statin treatment and myopathy in the de novo-treated patients}

In all, 17 patients (14\%) of the patients experienced myopathy. Seventeen percent of the women and $12 \%$ of the men had myopathy; all of which had myalgia. For women who started statin treatment, the risk ratio (RR) was 1.52 [95 \% CI 1.37; 1.66] for myopathy compared to men. There were no cases of myositis or rhabdomyolysis. All patients had CK values within the reference range throughout the study.

Twenty-six percent of the elderly ( $\geq 75$ years) had myopathy as compared to $14 \%$ of the other patients, RR 1.84 [95\% CI $1.61 ; 2.06]$. Given the limited number of elderly in the study, no further analysis was made on the differences between these age groups or the interaction between age and gender.

Table 1 Baseline demographic and disease characteristics

\begin{tabular}{|c|c|c|c|c|}
\hline Patient characteristics at baseline & Total $(N=180)$ & Women $(N=89)$ & $\operatorname{Men}(N=91)$ & $p^{*}$ \\
\hline Age (years), mean (SD) & $64.7(10.4)$ & $68.1(8.9)$ & $61.3(10.6)$ & 0.001 \\
\hline Age $>75$ years, $n(\%)$ & $33(18.3)$ & $22(24.7)$ & $11(12.1)$ & 0.034 \\
\hline Low CVD risk, $n(\%)$ & $8(4.4)$ & $3(3.4)$ & $5(5.5)$ & 0.720 \\
\hline Moderate CVD risk, $n(\%)$ & $87(48.3)$ & $55(61.8)$ & $32(35.2)$ & 0.001 \\
\hline High CVD risk, $n(\%)$ & $36(20.0)$ & $11(12.4)$ & $25(27.5)$ & 0.022 \\
\hline Very high CVD risk, $n(\%)$ & $49(27.2)$ & $20(22.5)$ & $29(31.9)$ & 0.180 \\
\hline Muscular pain/soreness VAS score, mean (SD) & $1.9(2.2)$ & $2.3(2.36)$ & $1.5(2.0)$ & 0.822 \\
\hline
\end{tabular}

*Analysis for significance on continuous data level: independent t-sample test used. Levene's test for equality of variances. Significance value two-tailed. On categorical data on ordinal or nominal level, significance was analyzed with chi-squared test/Fishers exact test, using non-parametric Levene's test Additional patient characteristics at baseline are shown in Supplementary Table S1 
All patients with myopathy had been prescribed simvastatin, mean dose $25.3 \mathrm{mg}$ (SD10.1) as compared to patients without myopathy $22.4 \mathrm{mg}$ (SD 8.7), $p=0.235$. Women in the myopathy group had a mean dose $21.0 \mathrm{mg}$ (SD7.4) as compared to $22.5 \mathrm{mg}$ (SD8.6) for women without myopathy, $p=0.626$. The mean dose for men in the myopathy group was $31.4 \mathrm{mg}$ (SD10.7), as compared to $23.7 \mathrm{mg}$ (SD 9.4) for men without myopathy, $p=0.017$.

All patients but one (16/17) with myopathy noticed the symptoms within the first month of statin treatment, and the 17 th patient had symptoms shortly after a dose increase after 6 months of treatment.

Muscle pain increased with an average of 6.0 (SD 2.2) on NRS, in women +5.3 points (SD 2.6), in men +7.0 (SD $2.5)$. The intensity of myopathy was graded as mild for $12 \%(2 / 17)$ (50\% women), as moderate for $35 \%(6 / 17)$ (67\% women), and as severe for $53 \%$ (9/17) (56 \% women). Sixty-seven percent reported that the muscular symptoms affected their daily life activities to a "moderate or severe" extent, $80 \%$ of the women (8/10), and $43 \%(3 / 7)$ of the men $(p=0.001)$.

Patients with both muscular pain and weakness reported that their daily activities were affected to a greater extent than patients with pain only.

Myopathy was more frequent among patients at "very high CVD risk" than the other CVD risk categories $(p=0.048)$. There was no difference in other patient characteristics such as body weight or renal function, see Supplementary Table S2.

\section{Sub-analysis of the de novo group}

Among the patients with myopathy, $76 \%$ reported other ADRs as compared to $21 \%$ of the patients without myopathy $(N=103 ; p=0.002)$. These ADRs were also noted during the first follow up period. Twenty-three percent of the patients reported 38 "other ADRs". Twenty-nine percent of the women and $18 \%$ of the men reported at least one other ADR. There were 16 reports of sleep disturbance, 15 of gastrointestinal problems, and 5 reports of skin rash. Elevated liver enzymes were observed in two patients.

\section{The switch group}

Among patients with muscular symptoms at study start in the "switch" group, the symptoms resolved within 3 months in 17 of $25(68 \%)$. These patients continued their statin treatment throughout the study. In the other patients ( $32 \%$; all women), the muscular symptoms persisted despite additional switches and/or decreased statin dose. These patients discontinued statin treatment before the study ended.

\section{Discussion}

In our study, we examined the frequency of myopathy among women and men on statin treatment in usual care including its time to onset and remission. We found that among all subjects, $14 \%$ experienced myopathy, $17 \%$ of the women, and $12 \%$ of the men. All cases of myopathy were myalgia with CK levels within normal range. This frequency of myalgia is consistent with $13 \%$ reported by Riphagen et al. [7]. However, in that study, the assessment of the relation between myalgia and statin treatment was made by the patients. Our results represent a cautious estimate of the myopathy frequency since we included only cases assessed as at least probable.

As in several other studies, we also found that myopathy was overrepresented among women and patients older than 75 years $[20,24,30]$. We had $50 \%$ women in our study population which reflect the gender distribution of the patients who purchased statin prescription in Stockholm County during this period. The study population did not fully reflect the proportion of elderly among statin-treated patients in the region, 18 versus $28 \%$ (The Swedish Prescribed Drug Register). Information about the percentage of elderly in other studies is not readily available, since most studies only report mean age of the patients.

Statin myopathy is considered to be dose-dependent. We also found a significant difference in mean dose between men with and without myopathy, but between the women, there was no difference. However, $20 \%$ of the women in the myopathy group had a concomitant medication with a potential to inhibit CYP3A4, thereby increasing the plasma concentration of some statins. Even so, these findings point to the need to better understand the mechanisms of statin-induced myalgia in women and men, respectively.

The myopathy occurred within the first month of treatment, as previously shown $[20,31]$. There were no gender disparities in time to onset. However, men reported higher pain intensity, and women reported greater impact on daily life activities. The analysis also indicated that patients at very high risk for CVD were $30 \%$ more likely to experience myopathy as compared to those with lower degrees of CVD risk. From a public health perspective, it is a challenge if those who would benefit the most from statin treatment would tolerate it the least. The unsatisfactory low adherence during long-term therapy, as has been demonstrated in several studies [32-34], may have a two-folded background. It seems likely that early discontinuation is caused by myopathy and/or other ADRs, since these symptoms usually occur within the first treatment month. For the late discontinuers, other factors such as "lack of motivation" to continue a risk modifying treatment could play a bigger role. Therefore, the time slot for assessment of long-term adherence is critical for the final estimate.

Of those already experiencing myopathy at the time of inclusion, the symptoms resolved in $68 \%$ of the patients after 
switch to another statin. A similar high percentage of successful switches has been reported by Harris et al. [35]. Our subanalysis showed that the vast majority of patients with a myopathy also reported other statin-related ADRs, which raises the question of common underlying mechanisms.

Further studies on common as well as gender specific causes of myopathy and other ADRs are warranted to enable an optimization of statin treatment to further improve the secondary prevention of CVD in women and men. Our study suggests special considerations of the gender difference, women appearing to have more side effects and larger impact on daily life activities than men.

Compliance with ethical standards This study was approved by the Regional Ethics Committee in Stockholm and the Swedish Medical Products Agency (MPA) EudraCT 2006-00,486-34. The study complied with the Declaration of Helsinki of The World Medical Association and the International Conference of Harmonization Guideline of Good Clinical Practice (ICH-GCP, E6). All participants signed an informed consent before the start of the study.

Conflict of interest ME has received lecture fees from MSD and AstraZeneca, served as a consultant to Amgen, Sanofi and NovoNordisk and received grant support from MSD.

Funding Financial support was provided through the regional agreement on training and clinical research (ALF) between Karolinska Institutet and Stockholm County Council, unrestricted grants from Pfizer and the Swedish Science Council (04496 AR) and funds from the Karolinska Institutet.

Open Access This article is distributed under the terms of the Creative Commons Attribution 4.0 International License (http:// creativecommons.org/licenses/by/4.0/), which permits unrestricted use, distribution, and reproduction in any medium, provided you give appropriate credit to the original author(s) and the source, provide a link to the Creative Commons license, and indicate if changes were made.

\section{References}

1. Mihaylova B, Emberson J, Blackwell L, Keech A, Simes J, Barnes $\mathrm{EH}$, et al. (2012) The effects of lowering LDL cholesterol with statin therapy in people at low risk of vascular disease: metaanalysis of individual data from 27 randomised trials. Lancet 380(9841):581-590

2. Shepherd J, Cobbe SM, Ford I, Isles CG, Lorimer AR, MacFarlane PW, et al. (1995) Prevention of coronary heart disease with pravastatin in men with hypercholesterolemia. West of Scotland coronary prevention study group. N Engl J Med 333(20):1301-1307

3. Downs JR, Clearfield M, Weis S, Whitney E, Shapiro DR, Beere PA, et al. (1998) Primary prevention of acute coronary events with lovastatin in men and women with average cholesterol levels: results of AFCAPS/TexCAPS. Air force/Texas coronary atherosclerosis prevention study. JAMA 279(20):1615-1622

4. Baigent C, Keech A, Kearney PM, Blackwell L, Buck G, Pollicino C, et al. (2005) Efficacy and safety of cholesterol-lowering treatment: prospective meta-analysis of data from 90,056 participants in 14 randomised trials of statins. Lancet 366(9493):1267-1278
5. Allen Maycock CA, Muhlestein JB, Horne BD, Carlquist JF, Bair TL, Pearson RR, et al. (2002) Statin therapy is associated with reduced mortality across all age groups of individuals with significant coronary disease, including very elderly patients. J Am Coll Cardiol 40(10):1777-1785

6. The Post Coronary Artery Bypass Graft Trial Investigators (1997) The effect of aggressive lowering of low-density lipoprotein cholesterol levels and low-dose anticoagulation on obstructive changes in saphenous-vein coronary-artery bypass grafts. N Engl J Med 336(3):153-162

7. McCarthy M (2015) New cholesterol drugs are overpriced, independent analysis finds. BMJ 351:h4864

8. Riphagen IJ, van der Veer E, Muskiet FA, DeJongste MJ (2012) Myopathy during statin therapy in the daily practice of an outpatient cardiology clinic: prevalence, predictors and relation with vitamin D. Curr Med Res Opin 28(7):1247-1252

9. Buettner C, Davis RB, Leveille SG, Mittleman MA, Mukamal KJ (2008) Prevalence of musculoskeletal pain and statin use. J Gen Intern Med 23(8):1182-1186

10. Harper CR, Jacobson TA (2010) Evidence-based management of statin myopathy. Curr Atheroscler Rep 12(5):322-330

11. Bays H (2006) Statin safety: an overview and assessment of the data-2005. Am J Cardiol 97(8 A):6C-26C

12. Bhardwaj SS, Chalasani N (2007) Lipid-lowering agents that cause drug-induced hepatotoxicity. Clin Liver Dis 11(3):597-613

13. the Scandinavian Simvastatin Survival Study (4S) (1994) Randomised trial of cholesterol lowering in 4444 patients with coronary heart disease. Lancet 344(8934):1383-1389

14. Sacks FM, Pfeffer MA, Moye LA, Rouleau JL, Rutherford JD, Cole TG, et al. (1996) The effect of pravastatin on coronary events after myocardial infarction in patients with average cholesterol levels. Cholesterol and recurrent events trial investigators. N Engl J Med 335(14):1001-1009

15. The Long-Term Intervention with Pravastatin in Ischaemic Disease (LIPID) Study Group (1998) Prevention of cardiovascular events and death with pravastatin in patients with coronary heart disease and a broad range of initial cholesterol levels. N Engl J Med 339(19):1349-1357

16. Cannon CP, Braunwald E, McCabe CH, Rader DJ, Rouleau JL, Belder R, et al. (2004) Intensive versus moderate lipid lowering with statins after acute coronary syndromes. N Engl J Med 350(15):1495-1504

17. Thompson PD, Clarkson PM, Rosenson RS (2006) An assessment of statin safety by muscle experts. Am J Cardiol 97(8 A):69C-76C

18. Hedenmalm K, Alvan G, Ohagen P, Dahl ML (2010) Muscle toxicity with statins. Pharmacoepidemiol Drug Saf 19(3):223-231

19. Pasanen MK, Neuvonen M, Neuvonen PJ, Niemi M (2006) SLCO1B1 polymorphism markedly affects the pharmacokinetics of simvastatin acid. Pharmacogenet Genomics 16(12):873-879

20. Bruckert E, Hayem G, Dejager S, Yau C, Begaud B (2005) Mild to moderate muscular symptoms with high-dosage statin therapy in hyperlipidemic patients - the PRIMO study. Cardiovasc Drugs Ther 19(6):403-414

21. Ridker PM, Danielson E, Fonseca FA, Genest J, Gotto AM Jr, Kastelein JJ, et al. (2008) Rosuvastatin to prevent vascular events in men and women with elevated C-reactive protein. N Engl J Med 359(21):2195-2207

22. Thompson PD, Clarkson P, Karas RH (2003) Statin-associated myopathy. JAMA 289(13):1681-1690

23. Grundy SM (2005) The issue of statin safety: where do we stand? Circulation 111(23):3016-3019

24. Pasternak RC, Smith SC Jr, Bairey-Merz CN, Grundy SM, Cleeman JI, Lenfant C (2002) ACC/AHA/NHLBI clinical advisory on the use and safety of statins. J Am Coll Cardiol 40(3):567-572

25. Ballo P, Balzi D, Barchielli A, Turco L, Franconi F, Zuppiroli A. (2016) Gender differences in statin prescription rates, adequacy of 
dosing, and association of statin therapy with outcome after heart failure hospitalization: a retrospective analysis in a community setting. Eur J Clin Pharmacol 72(3):311-319

26. Reiner Z, Catapano AL, De Backer G, Graham I, Taskinen MR, Wiklund O, et al. (2011) ESC/EAS guidelines for the management of dyslipidaemias: the task force for the management of dyslipidaemias of the European Society of Cardiology (ESC) and the European Atherosclerosis Society (EAS). Eur Heart J 32(14): 1769-1818

27. Brooks R (1996) EuroQol: the current state of play. Health Pol 37(1):53-72

28. Edwards IR, Aronson JK (2000) Adverse drug reactions: definitions, diagnosis, and management. Lancet 356(9237):1255-1259

29. Holbrook A, Wright M, Sung M, Ribic C, Baker S (2011) Statinassociated rhabdomyolysis: is there a dose-response relationship? Can J Cardiol 27(2):146-151

30. Walsh JM, Pignone M (2004) Drug treatment of hyperlipidemia in women. JAMA 291(18):2243-2252
31. Kasliwal R, Wilton LV, Cornelius V, Aurich-Barrera B, Shakir SA (2007) Safety profile of rosuvastatin: results of a prescription-event monitoring study of 11,680 patients. Drug Saf 30(2):157-170

32. Avorn J, Monette J, Lacour A, Bohn RL, Monane M, Mogun H, et al. (1998) Persistence of use of lipid-lowering medications: a cross-national study. JAMA 279(18):1458-1462

33. Benner JS, Glynn RJ, Mogun H, Neumann PJ, Weinstein MC, Avorn J (2002) Long-term persistence in use of statin therapy in elderly patients. JAMA 288(4):455-461

34. Ellis JJ, Erickson SR, Stevenson JG, Bernstein SJ, Stiles RA, Fendrick AM (2004) Suboptimal statin adherence and discontinuation in primary and secondary prevention populations. J Gen Intern Med 19(6):638-645

35. Harris LJ, Thapa R, Brown M, Pabbathi S, Childress RD, Heimberg $\mathrm{M}$, et al. (2011) Clinical and laboratory phenotype of patients experiencing statin intolerance attributable to myalgia. J Clin Lipidol 5(4):299-307 